\title{
SERVENTIAS EXTRAJUDICIAIS COMO INSTRUMENTO DE PACIFICAÇÃO SOCIAL - UM MODELO VENCEDOR POR SUA PRÓPRIA NATUREZA
}

\author{
Weslley Bormann ${ }^{1}$ \\ Greissy Cristine Thomazi Faber ${ }^{2}$
}

Resumo: Não é de hoje que o Judiciário Brasileiro vem enfrentando um dos motivos de maiores reclamações da sociedade que é especificamente a demora na prestação jurisdicional. Essa patologia que gera tensão e angústia pode ser eficazmente atenuada com o auxílio das serventias extrajudiciais que por sua própria natureza como descrito no artigo $1^{\circ} \mathrm{da}$ Lei 8.935/94, garantem a publicidade, autenticidade, segurança e eficácia dos atos jurídicos. Nesse passo, após o sucesso visível da Lei 11.441/07 que deu azo as serventias realizarem separações, divórcios e inventários é que se quer chamar atenção para essa via econômica, célere e muito segura que certamente contribuirá na pacificação social.

Palavras-chave: Serventias extrajudiciais. Instrumento. Pacificação social.

\section{INTRODUÇÃO}

Bem pontuou Guilherme Arruda de Oliveira que "a morosidade na prestação jurisdicional tem frustrado direitos, desa-

1 Advogado. Especialista em Direito do Trabalho pela AMATRA; Especialista em Direito Civil, Negocial e Imobiliário pela Anhanguera; Especialista em Direito de Família e Sucessões pela Anhanguera; Especializando em Direito Público pela FURB; Especializando em Prática Jurídica pela FURB. ESMESC. E-mail: weslleybormannadv@hotmail.com.

2 Bacharel em Direito. Especializando em Direito Público pela FURB. ESMESC. E-mail: greissy_faber@hotmail.com 
creditado o poder público, especialmente o poder judiciário e afrontando os indivíduos. A justiça que tarda falha. E falha exatamente porque tarda." ${ }^{3}$

Nessa linha é fácil concluir que o autor com razão é prejudicado pelo tempo da justiça na mesma medida em que o réu sem razão é por ela beneficiado (MARINONI, 2013).

Essa demora, também para os direitos não patrimoniais é terrível como bem elucida Luiz Guilherme Marinoni (2013):

A dimensão do tempo é também inocultável quando se tomam em consideração os direitos não patrimoniais, como os direitos de personalidade e o direito ao meio ambiente. Esses direitos, como é pouco mais do que evidente, não podem se dar ao luxo de esperar o 'tempo normal da justiça', pena de serem transformados em direitos à indenização. O tempo do processo inutiliza-os, dando a impressão de que todos, ao contrário do que está proclamado na lei, podem violá-los caso se disponham a pagar por eles, prestando indenização. A morosidade da justiça prejudica a efetividade dos direitos fundamentais.

Atento a esse anseio social que clama por um judiciário mais célere e eficaz é que o legislador introduziu no ordenamento jurídico brasileiro de forma inovadora a Lei 11.441/07 que alterou o Código de Processo Civil, possibilitando a realização de inventário, partilha, separação consensual e divórcio consensual por via administrativa.

Sobre o tema bem pontuou Luiz Guilherme Loureiro (2011):

Esta medida favorece a celeridade dos atos, sem prejuízo à sua segurança jurídica. Certamente também resulta em sua diminuição de custos, pois, embora haja necessidade de pagamento de emolumentos pela lavratura de escritura pública (salvo para as pessoas reconhecidamente pobres),

3 http://www.direitonet.com.br/artigos/exibir/1706/A-demora-na-entrega-da-prestacao-jurisdicional-e-a-responsabilidade-do-Estado 
os honorários advocatícios tenderão a ser menores (o advogado não precisará acompanhar uma ação por vários meses), e não será paga a taxa judiciária e outras despesas decorrentes do processo judicial.

Como se percebe de antemão, é um procedimento econômico e célere para as partes, além de trazer inúmeras outras vantagens como segue dissertando o Autor assinalado em epígrafe:

Trata-se de um mecanismo extrajudicial de administração pública de interesses privados que o notário substitui o juiz na recepção de vontade das partes em relação jurídica marcada pela inexistência de litígio. Obviamente, o notário deverá analisar se estão presentes os requisitos legais para a realização da separação consensual ou do divórcio consensual antes de lavrar o ato notarial competente. A escritura pública, portanto, substitui a sentença judicial como ato de homologação da vontade das partes e confere eficácia à dissolução da sociedade ou do vínculo conjugal, independentemente de homologação do juiz, podendo e devendo ser registrada no Serviço de Registro Civil de Pessoas Naturais e também no Registro de Imóveis, na hipótese de existência de direitos reais sobre bens imobiliários.

Com o advento da Lei em estudo, só no ano de 2012 conforme dados da Anoreg/SC ${ }^{4}$, foram realizados 5.300 (cinco mil e trezentos) inventários, e mais de 2.000 (dois mil) divórcios, o que sem dúvida demonstra que a população está satisfeita com os serviços prestados, totalizando nada menos que 7.300 (sete mil e trezentas) ações que deixaram de desaguar no Poder Judiciário Catarinense.

Mas é de se perguntar o porquê as Serventias são capazes de fazer às vezes do judiciário. Qual o fundamento jurídico e que tipo de segurança esses serviços transmitem para a população e para o próprio Judiciário?

4 ANOREG/SC: Associação dos Notários e Registradores do Estado de Santa Catarina. Dados obtidos em 18/06/2013 via e-mail, anoregsc@anoregsc.org.br. 
Respondendo aos questionamentos acima é que se disseca a atividade nos tópicos seguintes, nos atendo mais aos Tabelionatos de Notas que é onde naturalmente os primeiros passos foram dados conforme ditames da Lei 11.441/07.

\section{A ATIVIDADE NOTARIAL E DE REGISTROS}

A Constituição Federal dispõe no art. 236 que "Os serviços notariais e de registro são exercidos em caráter privado, por delegação do Poder Público”.

Temos assim que as atividades de notas e de registro constituem funções públicas que, pelo disposto no artigo em epígrafe, não são executadas diretamente pelo Estado, mas sim, por meio de delegação a particulares.

Luiz Guilherme Loureiro (2011) completa:

Os notários e registradores, portanto, são profissionais do direito que exercem uma função pública delegada pelo Estado. Tais atividades são desempenhadas em caráter privado, sem que os profissionais que as exerçam integrem o corpo orgânico do Estado.

Tais profissionais são agentes públicos, mas não considerados funcionários públicos, pelo contrário, são considerados particulares em colaboração com a Administração, compondo uma terceira categoria de agentes públicos, ao lado dos agentes políticos e dos funcionários públicos. Por não serem servidores públicos também não estão adstritos a aposentadoria compulsória (ADI 2.602/MG).

Quanto à remuneração, por não integrarem a estrutura do funcionalismo não são remunerados pelos cofres públicos, a remuneração pela atividade provém de particulares, nesse ponto, bem asseverou o então Ministro do Supremo Tribunal Federal Carlos Ayres Brito, na ADI 2.602/MG:

[...] enfim, as atividades notariais e de registro não se inscrevem no âmbito das remunerações por 'tarifa' ou 'preço público', mas no círculo das 
que se pautam por uma tabela de emolumentos, jungidos estes a normas gerais que se editam por lei necessariamente federal. Características de todos destoantes, repise-se, daquelas que são inerentes ao regime dos serviços públicos.

Para o direito penal, entretanto, esses profissionais são considerados funcionários públicos em sentido amplo, podendo responder por prevaricação, peculato, corrupção passiva, concussão entre outros crimes contra a administração.

Traduzindo em miúdos, as atividades profissionais de notas e de registro são de titularidade do Estado, mas a pessoa jurídica de direito público não a exerce diretamente, deve, por imposição do art. 236 da Constituição Federal, delegá-la ao particular.

Luiz Guilherme Loureiro (2011), bem resume esses profissionais, ao concluir que:

Portanto, o notário e o registrador são profissionais do direito, dotados de fé pública, a quem é delegado o exercício da atividade notarial e de registro. Estes profissionais gozam de independência no exercício de suas atribuições e só perderão a delegação nas hipóteses previstas em lei (art. 28). Como titulares de uma função pública, delegada pelo Estado, os notários e registradores têm suas atividades fiscalizadas pelo Poder Judiciário (art. 236, \$1º, da CF).

É fácil perceber assim que os notários e registradores por sua essência exercem uma atividade jurídica e não uma atividade administrativa material como obras ou serviços públicos.

Por exercerem uma atividade essencialmente pública, mas de maneira privada, a consequência natural é que tais profissionais são independentes, devendo obediência apenas à lei e aos regulamentos e normas editadas pelo Poder Judiciário.

Assim, por exemplo, quando uma pessoa qualquer apresenta um requerimento de separação, divórcio, inventário ou qualquer outro serviço da competência da serventia, o Tabelião pode e deve como obrigação inerente a sua função exercer a qualificação e recusar a lavratura se não perceber presente 
alguma formalidade ou requisito imposto pela lei, como falta da certidão de casamento, falta da certidão de propriedade de bens imóveis ou direitos a eles relativos.

Quanto ao espaço territorial para o exercício das atividades, os limites geográficos em verdade são pela lei impostos apenas aos registradores de imóveis e de pessoas naturais como se verifica no art. 12 da Lei 8.935/94.

Nesse sentido bem esclareceu o Conselho Nacional de Justiça no Procedimento de Controle Administrativo - PCA 642, onde asseverou que somente o serviço de notas não está sujeito a uma determinada limitação territorial. "Logo, apenas o notário não está sujeito a uma determinada limitação territorial. O tabelião pode lavrar atos, ainda que as partes e os bens pertinentes sejam domiciliados ou estejam localizados em outras comarcas ou territórios”. (LOUREIRO, 2011)

A porta de entrada na atividade se dá por concurso público de ingresso ou remoção, sendo dois terços das vagas providas por ingresso e um terço por remoção, sempre realizadas pelo Judiciário que como exposto também fiscaliza o exercício da atividade.

No tocante a responsabilidade civil, a regra é a do $\$ 6^{\circ}$ do art. 37 da Constituição Federal que salienta a teoria do risco administrativo, portanto, em que pese em outros momentos ter tido certa discussão sobre o assunto, hoje é tranquilo o entendimento de que a responsabilidade é objetiva.

Por tudo que aqui se delineou percebe-se que os profissionais objeto desse trabalho possuem uma natureza jurídica sui generis com características próprias.

\subsection{Fé pública}

O Estado nas suas múltiplas e infindáveis tarefas como representantes legais do povo, outorga a certos cidadãos, pautados sempre na Constituição Federal, o poder de representação para tarefas específicas, tarefas essas de grande repercussão, pois garante assim a paz social e harmonia entre as pessoas. 
Dentre essas pessoas estão inseridas o Oficial de Registros Públicos ou Registrador e o Notário ou Tabelião, entre outros, cuja participação nos negócios lhes atribui grandes responsabilidades uma vez que as atividades desenvolvidas dão como verdadeiros os atos praticados pelas partes em suas variáveis tratativas.

Para Carlos Fernando Brasil Chaves e Afonso Celso F. Rezende (2011) fé pública proporciona tranquilidade à sociedade, asseverando que:

Esse modo de declarar que determinados atos praticados ou ritos perseguidos estão perfeitamente estribados em ditames legais é conhecido como fé pública, ou seja, é real, iniludível, verídico e legal, ficando as partes envolvidas na ação perfeitamente abrigadas e aquecidas pelo Direito, isentas de qualquer dúvida - claro, até prova em contrário.

Acrescentam ainda os mesmos doutrinadores (CHAVES; REZENDE, 2011):

A fé pública, nesta conjuntura individualizadora [...] é uma das mais amplas já conhecidas, pois ao detentor dessa atribuição cabe a expressão da verdade, ou melhor, vige a crença popular de ser correto, autentico em tudo aquilo que dita e escreve, salvo incontestável prova em contrário, já que a sociedade não pode ser traída em nenhuma hipótese.

Verifica-se assim consoante determinação do art. $3^{\circ}$ da Lei 8.935/94, que ao notário e ao registrador é atribuída, pelo Estado, a fé pública conferindo-lhes presunção legal de autenticidade quando apõe seu sinal público nos documentos, razão pela qual são extremamente seguros e confiáveis tais serviços.

\subsection{Tabelionato de notas. Competência e atribuições do notário}

A Lei 8.935/94 regulamenta o art. 236 da Constituição Federal e trás no bojo dos arts. $6^{\circ}$ ao $9^{\circ}$ do diploma as atribui- 
ções e competências dos notários que interessam para o presente trabalho, confira-se:

Art. 6-Aos notários compete:

I - formalizar juridicamente a vontade das partes;

II - intervir nos atos e negócios jurídicos a que as partes devam ou queiram dar forma legal ou autenticidade, autorizando a redação ou redigindo os instrumentos adequados, conservando os originais e expedindo cópias fidedignas de seu conteúdo;

III - autenticar fatos

Art. $7^{\circ}$ - Aos tabeliães de notas compete com exclusividade:

I - lavrar escritura e procurações, públicas;

II - lavrar testamentos públicos e aprovar os cerrados;

III - lavrar atas notariais;

IV - reconhecer firmas;

$\mathrm{V}$ - autenticar cópias.

Parágrafo único. É facultado aos tabeliães de notas realizar todas as gestões e diligencias necessárias ou convenientes ao preparo dos atos notariais, requerendo o que couber, sem ônus maiores que os emolumentos devidos pelo ato.

Art. $8^{\circ}$ - É livre a escolha do tabelião de notas, qualquer que seja o domicílio das partes ou o lugar de situação dos bens objeto do ato ou negócio.

Art. 9० - O tabelião de notas não poderá praticar atos de seu ofício fora do município para o qual recebeu delegação.

A atividade notarial é uma atividade jurídica, sendo que os notários valem-se de técnicas para bem formalizar a vontade das partes como exposto no inciso do I do art. $6^{\circ}$ em epígrafe.

Nesse sentido pondera Ricardo Guimarães Kollet (2008):

A função notarial atua basicamente sobre os atos de vontade: os negócios jurídicos e os atos jurídicos stricto sensu. A Lei confere aos notários em geral a tarefa de qualificar a vontade das partes manifestadas perante o agente da fé pública estatal, o qual, através de um processo de qualificação nota- 
rial - que se difere da qualificação registral porque esta é eminentemente documental -, vai depurar os propósitos de ordem moral ou econômica entabulados pelos interessados e erigi-los, ou não, à juridicidade. Se a qualificação for positiva, o notário irá formalizar juridicamente a vontade das partes. Ao contrário, se o processo de qualificação notarial for negativo, em função de inadequações de natureza subjetiva ou objetiva que porventura aflijam a vontade ou seu objeto, ela não merecerá ser formalizada pelo agente notarial.

Nesse sentido, para bem formalizar a vontade das partes, necessário será que o tabelião de notas ao receber a intenção das partes deverá absorver essa intenção e mandá-la para uma espécie de catalisador que se denomina processo de qualificação notarial que resulta no reconhecimento ou não de direitos subjetivos, expurgando-se assim os vícios que porventura afetem, amoldando-se aos preceitos de ordem pública ou privada determinadas pela legislação, razão pela qual é uma atividade jurídica.

Se for positiva a qualificação, inicia-se a segunda fase de atividade notarial que é o inciso II do art. 6º da Lei 8.935/94.

A fase seguinte é referente à documentação. Por meio dela, o notário, sempre após qualificar positivamente as declarações de vontade, as instrumentaliza, dentro dos ditames legais, prezando pelos requisitos de natureza formal e material.

Nessa esteira, é de se afirmar que é obrigatória a atuação dos notários em relação aos atos e negócios jurídicos aos quais a lei exige a forma especial de escritura pública.

Infere-se assim que o tabelião é protagonista de todos os negócios jurídicos que sejam relevantes para a sociedade.

\section{PRINCÍPIOS ESTRUTURANTES DA ATIVIDADE NOTARIAL}

\subsection{Da juridicidade ou da segurança social}

Este princípio orienta que o notário, no desempenho de suas funções típicas, deve garantir as partes a real eficácia do 
ato praticado, tendo em vista ser o notário um profissional do direito.

O princípio da segurança social é o mais abrangente, pela responsabilidade atribuída ao tabelião em formalizar juridicamente a vontade das partes, conforme reza o art. $6^{\circ}$ da Lei 8.935/94.

Para tanto, o notário tem como missão adentrar ao mérito do negócio, não devendo, praticar atos nulos nem anuláveis.

Demonstra-se assim que a segurança social é a finalidade do notário na formação do ato.

\subsection{Da profilaxia}

O princípio da profilaxia, conhecido também como prudência ou cautela notarial tem como diretriz a operacionalização do negócio ou ato sem vícios.

O notário molda os negócios jurídicos privados, prevenindo-se de riscos e incertezas, devendo ter sempre em mente a prevenção de litígios, atuando apenas em atos e negócios jurídicos onde não haja pretensão resistida e consequente lide, sendo imprescindível o consenso geral.

E mais, "o notário, no exercício regular de sua função, adianta-se a prevenir e precaver os riscos que a incerteza jurídica possa acarretar a seus clientes”. (BRANDELLI, 2009).

Deverá assim o notário como delegado especial do Estado, orientar os usuários sobre o melhor caminho a ser seguido para o deslinde da questão.

\subsection{Da imparcialidade ou moralidade}

Esse princípio tem como vetusto constitucional o disposto no caput do art. 37, o que nos conduz ao entendimento de que o notário deverá agir no cumprimento de suas atribuições, de forma igualitária e imparcial, in verbis:

Art. 37. A administração pública direta e indireta de qualquer dos Poderes da União, dos Estados, do Distrito Federal e dos Municípios obedecerá 
aos princípios de legalidade, impessoalidade, moralidade, publicidade e eficiência e, também, ao seguinte.

Deve o profissional buscar o equilíbrio no atendimento dos interesses particulares, não favorecendo a ninguém no desempenho de suas funções, agindo com lealdade para com os usuários.

\subsection{Da publicidade}

O princípio da publicidade aduz que sendo função notarial pública, é obrigação do notário atender ao interesse da coletividade, sendo o acervo notarial de livre consulta.

Nesse sentido Rufino Larraud apud Leonardo Brandelli (2009) aduz:

Função pública é aquela atividade própria e característica do Estado, pela razão de que a comunidade está interessada de maneira direta em sua organização e em seu cumprimento regular e contínuo.

Essa publicidade é informativa, ou seja, todo ato notarial arquivado na sede da serventia é público, decorrente da delegação pública, do caráter público que a lei atribui.

\subsection{Da rogatória ou da instância}

Este princípio traduz a ideia de que o notário deve ser provocado a praticar os atos da sua competência, não podendo agir de ofício, deve então o notário ser instado, acionado pelo usuário seja de forma tácita ou expressa.

\subsection{Da tecnicidade}

Tal princípio já desenhado em linhas pretéritas e corolário do art. 6 da Lei 8.935/94 informa que compete ao notário intervir nos atos e negócios jurídicos, autorizando a redação ou redigindo instrumentos adequados. 
E para tanto, "deve o notário ser um profundo conhecedor dos meios de realização pratica do direito, especialmente o notarial”. (BRANDELLI, 2009).

\subsection{Da economia}

Busca este princípio a busca pelo ato notarial mais econômico para as partes, devendo o notário escolher bem o ato a ser realizado, sempre em atendimento às necessidades e condições das partes, buscando gerar o menor custo possível aos usuários.

\subsection{Da imediação}

Esse princípio defende o adequado fluxo de ideias de que o notário, próximo das partes, compreenderá suas vontades e desejos oferecendo-lhes o melhor aconselhamento para gerar o melhor instrumento necessário para satisfazer os anseios das partes.

\section{REGISTRADOR DE IMÓVEIS}

De acordo com o art. 12 da Lei 8.935/94 ao oficial de Registro de imóveis compete notadamente a prática de registro de direitos reais relativos a imóveis situados em determinada circunscrição geográfica, além da prática de outros atos estampados no art. 167 da Lei 6.015/73.

Lacerda de Almeida apud Walter Ceneviva (2010) aduz que o serviço em tela possui duas funções diferentes:

$\mathrm{Na}$ primeira serve de cadastro à propriedade imobiliária. Assim ministra prova certa e irrefragável do estado dessa propriedade. Nesse aspecto, é suficiente, completo, independente; por meio dele se operam as mutações, alterações e extinções de direitos referente a imóveis. Numa segunda função, é espelho e indicador dos contratos que se passam, com relação à propriedade imobiliária, e nesta função está na dependência dos contratos 
celebrados; seu mister é trazê-lo à publicidade, facilitar o meio de conhece-los de pronto.

A função basilar do registro de imóveis é constituir repositório fiel da propriedade imóvel e dos negócios jurídicos que a ele diz respeito. Nesse ponto bem assevera Lafayette (1940):

A deslocação do domínio de uma pessoa para outra carece de uma manifestação visível, de um sinal exterior, que ateste e afirme aquele ato diante da sociedade. Exige-o a natureza do domínio. Direito absoluto (erga omnes), o domínio abriga a todos, pode ser oposto a todos; importa, pois, que todos conheçam as suas evoluções. Essa publicidade, ainda mais energicamente, reclama a segurança dos interesses ligados à propriedade; é ela necessária para prevenir as fraudes que a má-fé de uns, protegida pela clandestinidade, pudera preparar em prejuízo da boa-fé de outros.

O serviço de registro de imóveis, portanto, tem por escopo assegurar a publicidade, autenticidade, segurança e eficácia dos atos e negócios jurídicos relacionados à propriedade imobiliária.

\section{REGISTRO CIVIL DE PESSOAS NATURAIS}

O Estado confia ao Registro de Pessoas Naturais, nas palavras de Souza (2009) a responsabilidade:

[...] pela documentação referente ao estado civil dos cidadãos. É a principal fonte de informações estatísticas do governo, e constitui a prova da existência, capacidade e estado civil dos registrados, conforme termos dos artigos $9^{\circ}$ e 10 do Código Civil e artigos 29, 100 caput, 101, 102 e 104 da Lei 6.015/73.

Conforme ensinamentos de Ceneviva (2010), o Estado:

[...] tem no registro civil a fonte principal de referencia estatística: comete crime o oficial que não 
remeter, trimestralmente, à Fundação Instituto Brasileiro de Geografia e Estatística - IBGE os mapas de nascimentos, casamentos e óbitos. É base para que os governos decidam suas medidas administrativas e de política jurídica (BEVILÁQUA apud CENEVIVA, 2010). O indivíduo nele encontra meios de provar seu estado, sua situação jurídica. Fixam de modo inapagável, os fatos relevantes da vida humana, cuja conservação em assentos públicos interessa à Nação, ao indivíduo e a todos os terceiros (CENEVIVA, 2010). Seu interesse reside na importância mesma de tais fatos e, outrossim, na sua repercussão na existência do cidadão: ele é maior ou menor, capaz ou incapaz, interdito, emancipado, solteiro ou casado, filho, pai. É todo um conjunto de condições a influir sobre sua capacidade e sobre as relações de família, de parentesco e com terceiros. (CENEVIVA, 2010).

A Carta cidadã de 1988 , no art. 5º, LXXVI, é clara ao afirmar a importância do registro civil, ao assegurar a gratuidade do assento de nascimento e da certidão de óbito.

\section{REGISTRO CIVIL DAS PESSOAS JURÍDICAS}

Souza (2009) muito bem leciona acerca da competência e importância do Registro Civil das Pessoas Jurídicas:

Ao Registro Civil das Pessoas Jurídicas compete o registro de atos constitutivos de pessoas jurídicas sem natureza mercantil, com o fim de lhe atribuir a partir de então personalidade, bem assim das alterações que se seguirem. Ainda, são competentes para o registro de jornais, periódicos, oficinas impressoras, empresas de radiofusão e agencia de notícias.

Neste serviço, portanto serão inscritos os atos constitutivos das sociedades simples, associações, fundações e dos partidos políticos, além das matrículas de jornais, periódicos, oficinas impressoras, agências de notícias e empresas de radiofusão. 
A existência de um registro especial para pessoas jurídicas civis é conveniente, para melhor distingui-las das comerciais. Ajusta-se ao sistema legal brasileiro, que tem resistido à unificação dos Códigos Civil e Comercial.

O registro civil da pessoa jurídica, além de lhe atribuir personalidade de direito, pode produzir outros efeitos ${ }^{5}$. Assim, por exemplo, habilita o partido político a submeter seus estatutos ao TSE. A associação civil filantrópica, de caráter cultural, cuja finalidade estatutária principal, constante do registro público, seja a de dar a instituições culturais oficiais da União, é equiparada a projeto cultural de plano de atividade.

\section{TABELIONATO DE PROTESTO}

Incumbe a essa Serventia o Protesto de títulos, e Loureiro (2011) assegura:

[...] a afirmação solene em ato público formado por notário, com finalidade iminente de provar, com segurança jurídica, o descumprimento de obrigação cambial. Através do Protesto se prova de forma precisa e cristalina a falta de aceite ou de pagamento de um título e ainda a falta de devolução de uma duplicata.

Percebe-se assim que o protesto hoje prova a inadimplência de obrigações decorrentes de documentos de dívida (art. 1º da Lei 9492/97); interrompe a prescrição (202,III, CC); dá o efeito da constituição da mora na compra e venda com reserva de domínio (1071, CPC) e alienação de bens móveis (Dec. Lei 911/69); é pressuposto de admissibilidade para a ação de execução de contrato de câmbio (art. 75, Lei 4728/65); caracteriza o estado de falência (art. 94,I, da Lei 11.101/05), bem como fixa a data para pagamento da letra de câmbio a certo termo de vista em que há recusa de aceite.

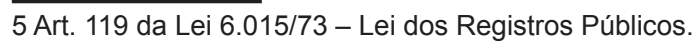


Desse modo se infere que o serviço de protesto possui três funções principais que são a probatória, a conservatória do direito do credor e a informativa.

\section{REGISTRO DE TÍTULOS E DOCUMENTOS}

No que compete ao Registro de Títulos e Documentos, Souza (2009) sustenta que sua função essencial é:

[...] dar publicidade a papéis particulares, autenticando-os a data e trazendo como efeito a sua "cognoscibilidade por todos os terceiros, aos quais o ato jurídico, desde que não atribuído a outros registros, é oponível" (CENEVIVA:206:287). Possui, ainda, uma competência residual para os registros a outro serviço registral.

Verifica-se assim que a principal função desse serviço é dar publicidade aos títulos particulares, mas não o único, pois ele tem a atribuição para registrar quaisquer documentos para fins de conservação.

Não se visa constituir direito no Registro de Títulos e Documentos, mas visa conferir publicidade e conservação dos documentos que instrumentalizam direitos e obrigações, garantindo a prova, validade e eficácia dos direitos e obrigações neles pactuados.

\section{O OFICIAL COMO INSTRUMENTO DE PACIFICAÇÃO SOCIAL}

Por tudo que se delineou no trabalho, percebe-se que esse profissional do direito possui todas as qualificações para exercer o importante papel de conciliador "desjudicializado", pois detém técnica, experiência e mecanismos para bem resolver as demandas consensuais postas.

Verificando a segurança ofertada pelos notários e o sucesso advindo da Lei 11.441/07 é que o Conselho Nacional de Justiça em 29.11.2010, instituiu a Resolução n. 125 que introduziu uma 
nova política de justiça alicerçada nos tratamentos dos conflitos por vias consensuais e não simplesmente por sentença.

Sob esse aspecto a Corregedoria do Estado de São Paulo, sempre atenta, logo se utilizou desse novo instrumento e de maneira inovadora autorizou a realização e conciliações e mediações no âmbito extrajudicial através do Provimento 17/2013.

O grande volume de processos e a mínima efetividade dos julgados, pelo número considerado de recursos e pela utilização selvagem da Justiça, resultaram na imprescindibilidade de se repensar o processo e o poder Judiciário, de modo a traduzir qual sociedade queremos no futuro. Nesse aspecto de nova visão, os mecanismos consensuais tem se mostrado como excelentes oportunidades não apenas de desafogo do judiciário, mas também como formas de construir soluções de integração para todos os envolvidos no conflito.

Antes de qualquer coisa é bom se que diga que trata-se um procedimento facultativo, ou seja, as partes poderão optar entre a solução clássica pelo Judiciário ou essa nova via, além do que o art. 3o do Provimento é claro ao dispor que apenas os direitos patrimoniais disponíveis poderão ser objeto das mediações e conciliações extrajudiciais.

Dessa forma, na prática, pelo menos em São Paulo funcionará assim: $O$ interessado, pessoa natural capaz ou pessoa jurídica, se dirige a uma serventia extrajudicial habilitada, onde protocola sua intenção, seu pedido e de pronto recebe a data da sessão reservada de mediação. Pode o requerimento ser feito em conjunto. Em seguida a serventia faz a notificação da parte contrária, para que compareça nos dias programados, sempre de modo facultativo. Essa data marcada como não poderia deixar de ser é flexível, de modo a atender melhor as partes, ou seja, podem os envolvidos pactuar uma data que melhor atender suas necessidades.

A intimação da parte contrária dar-se-á por qualquer meio idôneo de comunicação, como AR, meio eletrônico, ou mesmo a mais segura que é a notificação via Registro de Títulos e Docu- 
mentos da Comarca do domicilio de quem deva recebê-la, com as custas pagas sempre pelo interessado.

Estando todos presentes na sessão e obtida a composição com o acordo por todos assinado, essa ata será registrada em livro próprio denominado Livro de Mediação e Conciliação que poderá ser escriturado por meio eletrônico.

Cada parte recebe uma via do acordo, que será disponibilizada na internet com acesso restrito, mediante utilização de código.

A via disponibilizada as partes, possuí força executiva extrajudicial conforme art. 585, II, do Código de Processo Civil. As certidões e mesmo traslado do acordo ao contrário não terão força executiva.

Mesmo durante o procedimento o requerente poderá desistir, e cabe ao notário arquivar o procedimento e consignar essa providencia em livro próprio.

Ás custas e emolumentos serão com valor declarado de acordo com a expressão econômica apresentada. Os valores de emolumentos poderão ser exigidos previamente pelos oficiais, no entanto, se o pedido for arquivado sem o acordo, o valor será devolvido no percentual de $90 \%$, caso ocorra antes da sessão de conciliação, 50\% quando não se obtiver o acordo na sessão ou $40 \%$ quando por algum motivo a mediação for transferida para outra data.

As serventias como não poderiam deixar de ser atuarão em causas cíveis, como nos acidentes de trânsito, nas dívidas em geral, dano moral e material, indenizações, execuções, despejos para uso próprio, arrendamento rural e parceria agrícola, ressarcimento por danos em prédio urbano ou rústico, dentro outras inúmeras possibilidades, sempre de maneira consensual.

Não há dúvidas de que é uma excelente via para que a sociedade possa se sentir mais segura, além do que as vantagens como explanado, são várias, a começar pela satisfação de quem vai se utilizar desses serviços que são os usuários, porque são eles que irão resolver o problema com a intervenção de um terceiro qualificado para atuar. 
Nesse sentido, conciliadores e mediadores que são os próprios oficiais ou prepostos autorizados deverão ser suficientemente treinados para desenvolver bem esse tão importante papel, em consonância com o que dispôs a Resolução 125 do Conselho Nacional de Justiça, que estabeleceu a necessidade de formação dos mediadores.

\section{CONCLUSÃO}

A maneira clássica de solução de conflitos com a triangularização entre autor, juiz e réu é sem dúvida importante e necessária ferramenta para a mantença da ordem e pacificação social, no entanto, não podemos fechar os olhos para momento atual em que estamos vivendo, onde todos os poderes do Estado estão sendo questionados pela população através de manifestações. Ademais, não é de hoje que o Poder Judiciário vem encontrando dificuldades em conferir efetividade às demandas que são submetidas ao seu crivo, e os motivos são incontáveis.

Nesse passo, como modo de manter a qualidade dos serviços prestados a população, mas de maneira mais rápida, porque não delegar as serventias extrajudiciais soluções de questões de menor complexidade onde a transação seja possível?

Apenas para constar, no Estado de Santa Catarina, existem atualmente 584 serventias extrajudiciais, ou seja, seriam 584 postos de conciliação do qual a população poderia se valer para resolver seus conflitos, com a grande vantagem do Estado não gastar nada com isso, pois os 'postos' estão montados por seus respectivos delegados, além do que boa parte dos emolumentos seriam destinados ao próprio poder judiciário.

A solução, portanto mostra-se palpável, possível e segura.

Abstract: It is not today that the Brazilian judiciary is facing one of the reasons of the biggest complaints of the society that is specifically the delay in adjudication. This pathology that creates tension and anxiety can be effectively mitigated with the aid extrajudicial service roads that by its very nature 
as described in Article 1 of Law 8.935/94, provide advertising, authenticity, safety and efficacy of legal acts. In this step, after the visible success of Law 11.441/07 which triggered the service roads perform separations, divorces and inventories is that if you want to draw attention to this route economical, quick and very safe will undoubtedly help in social pacification.

Keywords: Rounds off court. Instrument. Social peace.

\section{REFERÊNCIAS}

BRANDELLI, Leonardo. Teoria Geral do Direito Notarial. 3. ed. São Paulo: Saraiva, 2009.

CENEVIVA, Walter, 1928. Lei dos Registros Públicos comentada. 20 ed. São Paulo: Saraiva, 2010.

CHAVES, Carlos Fernando Brasil; REZENDE, Afonso Celso F.

Tabelionato de Notas e o Notário Perfeito. Editora Millennium, 5º edição, 2011.

KOLLET, Ricardo Guimarães. Manual do Tabelião de Notas para Concursos e Profissionais. Rio de Janeiro: Forense, 2008.

LAFAYETTE. Direito das Cousas. 3a ed. Adap. Ao Código Civil por José Bonifácio de Andrade e Silva. Rio de Janeiro, Freitas Bastos, 1940.

LOUREIRO, Luiz Guilherme. Registros Públicos: Teoria e Prática. 2. Ed. Rio de Janeiro: Forense. São Paulo: MÉTODO, 2011.

MARINONI, Luiz Guilherme. Teoria Geral do Processo. 7a ed. rev, atual. e ampl.. - São Paulo: Editora Revista dos Tribunais, 2013. - (Curso de Processo Civil; v. 1).

SOUZA, José Volpato de. Serventias Extrajudiciais Prática Correicional. Ano 2009. 